\title{
The effect of retrieval goals on the content recalled from complex narratives
}

\author{
Elizabeth Dutemple ${ }^{1}$ [D $\cdot$ Signy Sheldon ${ }^{1}$ \\ Accepted: 19 July 2021 / Published online: 19 August 2021 \\ (C) The Psychonomic Society, Inc. 2021
}

\begin{abstract}
Memories are not always accurately recalled, and one factor that influences memory is the goal of retrieval. Evidence suggests that retrieving a memory to fit a social goal affects the content that is recollected, yet the nature of this effect, and whether this effect remains stable over time, is not fully understood. To this end, we compared the effect of retrieving a complex event (i.e., a narrative) motivated by a social versus an accuracy goal both immediately and after a 24-hour consolidation period. Three groups of young adults encoded audio narratives and recalled these narratives immediately (Session 1) and again after a 24-hour delay (Session 2). One group recalled the narratives to meet a social goal across both sessions (social); another group recalled the narratives for an accuracy goal across both sessions (accuracy); and a final group initially recalled the narratives for a social goal (Session 1) and then for an accuracy goal (Session 2 ; mixed). We found no effect of group on the number of details that described the overall theme (central details); however, a social goal significantly reduced the number of specific (episodic) details and altered the order in which the details were described. When the goal of retrieval changed across session (i.e., mixed group), the reduction in specific details remained but not the effect on detail order. These results demonstrate that socially motivated memory retrieval selectively alters the specific episodic content contained in the memory, leaving intact the thematic knowledge and overall structure of the memory.
\end{abstract}

Keywords Episodic memory $\cdot$ Retrieval $\cdot$ Narrative recall $\cdot$ Context effects

Episodic memory retrieval is considered to be a reconstructive process (Schacter \& Addis, 2007), such that the same experience can be recollected with different content depending on how it is remembered. This is an adaptive mnemonic function that allows past experiences to be accessed in a variety of ways to fit a person's current retrieval goals (Bluck \& Alea, 2002; Pillemer, 2001; Prebble et al., 2013; Sheldon et al., 2019). Some studies have illustrated this function by showing that people change how they described memories depending on the characteristics of who is listening to them (Pasupathi \& Hoyt, 2010; Pasupathi \& Oldroyd, 2015). Other studies have done so by manipulating the questions asked about a memory (e.g., Rudoy et al., 2009). Finally, a large body of work has examined how inducing different goals at retrieval can affect the content recovered from a memory (e.g., Dudukovic et al., 2004; Wade \& Clark, 1993). In the current study, we focus on

Signy Sheldon

signy.sheldon@mcgill.ca

1 Department of Psychology, McGill University, 2001 McGill Avenue, Montreal, QC H3A 1G1, Canada examining the effect of retrieving memories to fulfill a social goal (Alea \& Bluck, 2003; Bluck et al., 2005).

It is commonly found that people tend to recall past experiences less accurately when in social situations than when recalling a memory in nonsocial situations (Marsh, 2007). One study explored how and why participants spontaneously recalled memories and found that memories told to friendsfor a social purpose - tended to be recalled with memory distortions, including exaggerations or oversimplifications (Marsh \& Tversky, 2004). Another study compared how narratives were recalled when given an entertainment or accuracy goal (Dudukovic et al., 2004). In the former condition, participants were encouraged to recount the story as entertainingly as possible, which is often the case when recalling memories socially, whereas in the latter condition, participants were encouraged to be as accurate as possible when recounting the narratives. The narratives recalled in the entertainment condition contained fewer perceptual details and were less accurate than those recalled in the accuracy condition, even though the entertainment condition was associated with higher ratings of retrieval certainty. These findings suggest that introducing a social context encourages an individual to recall their experiences in a flexible manner, leading to more distorted 
recollections than retrieving narratives for the purpose of accuracy (also see Marsh et al., 2005; Tversky \& Marsh, 2000).

However, there remain open questions as to how social retrieval goals affect detailed memory recall. One question is whether a social goal affects certain types of details contained within a memory, particularly complex memories that contain a variety of information. An accepted detail division within complex events is between those that describe the overall event structure (i.e., the gist or theme) — central details - and those that describe specific sensory or contextual aspects (i.e., details peripheral to the story) - specific details. Studies have indicated that central and specific details are supported by different processing mechanisms and prone to different forgetting rates, with central details retained more robustly in memory and less subject to distortion than specific details (Alba \& Hasher, 1983; Sekeres et al., 2016; Conway et al., 1991; Thorndyke, 1977; for related emotional memory research, see Burke et al., 1992; Christianson, 1992; Heuer \& Reisberg, 1992). Since specific details of a memory are more likely to be forgotten than central details (Sekeres et al., 2016; Thorndyke, 1977), we reason that recovery of specific details from a memory is selectively affected by a retrieval goal.

Another question concerning the effects of a social retrieval goal on memory recall is the duration of the effect. The act of retrieval can alter the underlying memory trace such that certain details are added or excluded as a function of the overall content that is recalled (Dudai \& Eisenberg, 2004). In other words, when a memory is constructed with a certain set of details, these details will be strengthened within the memory trace, while any details that are not retrieved will be weakened and potentially removed from that memory. This hypothesis is supported by evidence demonstrating that updating a memory leads to previously encoded events integrating new information made available at retrieval, resulting in the distortion of that memory (for a classic example, see Loftus et al., 1978; for a review, see Schacter et al., 2011). Thus, we are interested in how a memory is initially retrieved to an induced retrieval goal will affect subsequent retrievals.

\section{Current study}

The current study sought to explore how a social retrieval goal affects the types of details recalled from a complex memory, and whether this effect is maintained over time despite possible changes to the retrieval goal. We first hypothesized that a social retrieval goal will affect the number of specific (peripheral) details used to recall a narrative, but not the number of central details (i.e., details pertaining to the core structure of a memory). Secondly, we hypothesized that inducing a social retrieval goal will impact access to details at a later retrieval time point, even when the retrieval goal changes. To test these hypotheses, we designed a between-groups experiment to compare the performance of three separate groups of participants: an accuracy group, a social group, and a mixed group. Participants in the accuracy group were instructed to recollect previously encoded narratives as accurately as possible, both immediately (Retrieval 1) and 24 hours (Retrieval 2) after encoding. Participants assigned to the social group were instructed to recall the narratives as if they were talking with a close friend at both time points. Finally, those assigned to the mixed group first recalled the narratives as if they were talking with a close friend (Retrieval 1), and then were instructed to recall the narratives as accurately as possible 24 hours later (Retrieval 2), thereby altering the retrieval goal.

The narrative descriptions were scored for central and specific details, allowing us to examine how certain retrieval goals alter the types of details used to recall memories. Additionally, we examined the order in which participants recounted the details when describing the narratives. Finally, as an exploratory analysis, we assessed the style in which the narratives were described with an automated text analysis tool (Linguistic Inquiry and Word Count [LIWC]; Pennebaker et al., 2015). Based on past research indicating that social retrieval goals affect the emotional tone and formality of memory recollections (Dudukovic et al., 2004; Marsh \& Tversky, 2004), we focused on two LIWC metrics that assess these dimensions: tone (positive/negative) and formality (casual, simple language/formal and logical thinking).

\section{Material and methods}

\section{Participants}

Sixty-three participants (11 males; mean age $=21.1, S E=0.35$; mean years of education $=14.6, S E=0.24$ ) were recruited either from the McGill University human participant pool or from online advertisements. Four participants were excluded from the final sample due to attrition $(n=3)$ and experimenter error $(n=$ 1). Each participant was randomly assigned to either the accuracy ( $N=24)$, social $(N=24)$, or mixed group $(N=15)$. Our sample size of 24 per group was estimated based on previous studies that reported similar effects using a between-subjects design (Adams et al., 1997); however, we were unable to reach our planned sample size for the mixed group due to laboratory closure from the COVID-19 pandemic. All participants were fluent English speakers and free from neuropsychological or psychiatric disorders. Participants were either compensated with course credit or at the rate of $\$ 10 /$ hour.

\section{Stimuli}

Two distinct story narratives were adapted from Speer and Zacks (2005) that depict everyday life events centering around 
a protagonist; a person receiving a present and a person searching for a job (for full story descriptions, see Speer \& Zacks, 2005). We created two separate versions of each story: one version narrated and audio-recorded by a female protagonist, and a second version narrated and audio-recorded by a male protagonist. For each version, we created a title that would serve as a retrieval cue (e.g., "Jim Gets a New Computer"; "Larry Is Searching for a Job"). All stories were approximately the same length (ranging between 197 to 222 seconds; see Table 1 for story characteristics). The stories were parsed according to specific details (specific elements of the story; e.g., "Larry didn't want to be a doctor") and thematic units (overarching themes or "central" details; e.g., "Larry is thinking of job options") and were then scored according to the guidelines informed by the Logical Memory Test, a subtest of the Wechsler Memory Scale (Wechsler, 2009).

\section{Procedure}

This experiment was conducted over two sessions across 24 hours. Session 1 included an encoding and initial retrieval phase (Retrieval 1), while Session 2 involved an additional retrieval phase (Retrieval 2; see Fig. 1 for a schematic of the design). The task was designed and administered using EPrime 2.0 software.

Encoding phase Participants were told they were going to listen to two stories. Female participants heard the female version of the stories, and male participants heard the male version. They were instructed to remember the stories in as much detail as possible for a later retrieval task. Critically, participants were not informed of the retrieval goal (i.e., social, accuracy) at this time. Once they were ready to begin, they were fitted with headphones and began listening to the narratives. The narrative titles were presented visually on the computer screen for 5 seconds, followed by the audio-recording of the story narratives. Each story was presented twice. At the end of the second presentation, participants rated how much they enjoyed the story $(1=$ not at all to $7=$ very $m u c h)$.

Retrieval 1 After an 8-minute delay, during which the participants played Sudoku, they were asked to recall the two previously encoded narratives in as much detail as possible,

Table 1 Number of specific details and thematic units according to story

\begin{tabular}{lll}
\hline & Specific details & Thematic units \\
\hline Jim Gets a New Computer & 73 & 7 \\
Larry Is Searching for a Job & 72 & 7 \\
\hline
\end{tabular}

according to their assigned retrieval goals (please refer to Dudukovic et al., 2004, for a detailed description of the instructions). During this session, the accuracy group received these instructions: "I would like you to close your eyes and imagine the story about Jim/Larry you heard earlier. I would like you to retell this story in a precise manner. It is very important that you tell the story exactly as it was told to you, as close to the same words as possible. So be as accurate as you can. Tell me how you remember this story as if you were trying to tell someone exactly what happened, almost like you are narrating a script of the event. It is important to keep this goal of remembering in mind." The social and mixed groups received these instructions: "I would like you to close your eyes and imagine the story about Jim/Larry you heard earlier. Now, I want you to imagine a scenario in which you would talk about this story like it was a memory. I want you to imagine you are surrounded by your friends. You are comfortable and relaxed. One of your friends asks you to tell everyone about that story of Jim/Larry. Tell me how you would describe this story in this situation. You don't need to tell me the story as it occurred but tell me how you would talk about the story when socializing with your friends. It is important to keep this goal of remembering in mind. You may want to imagine yourself as a storyteller with your friends." Participants were given 3 minutes to describe each narrative. After each recall, participants made Likert ratings about the vividness of their experience recalling the story $(1=$ not vividly at all to $7=$ very vividly) and the emotional valence of each story $(1=$ very sad to $7=$ very happy $)$, and then typed out a short descriptive title for any personal experience they may have had that reminded them of the story.

Retrieval 2 Participants came back into the lab 24 hours later to recount the same narratives as the day before, in a randomized order. As in Session 1, they were given approximately $3 \mathrm{mi}-$ nutes to recall each story. Participants in the accuracy and social groups were given the same instructions as in the first session, thus not changing the retrieval goal. However, participants in the mixed group were asked to recall the narratives to fit an accuracy retrieval goal rather than a social goal, as they did in Session 1, thereby changing the retrieval goal. After each recollection, they once again made vividness and emotional valence ratings as well as provided a brief caption of an associated personal memory.

\section{Scoring}

Details The narratives were recorded and subsequently transcribed. They were then scored according to thematic units and specific details (refer to Table 1). Thematic units, or central details, include any details that reflect the general narrative and broad turning points in the story (e.g., Larry begins building his $C V$ ). 


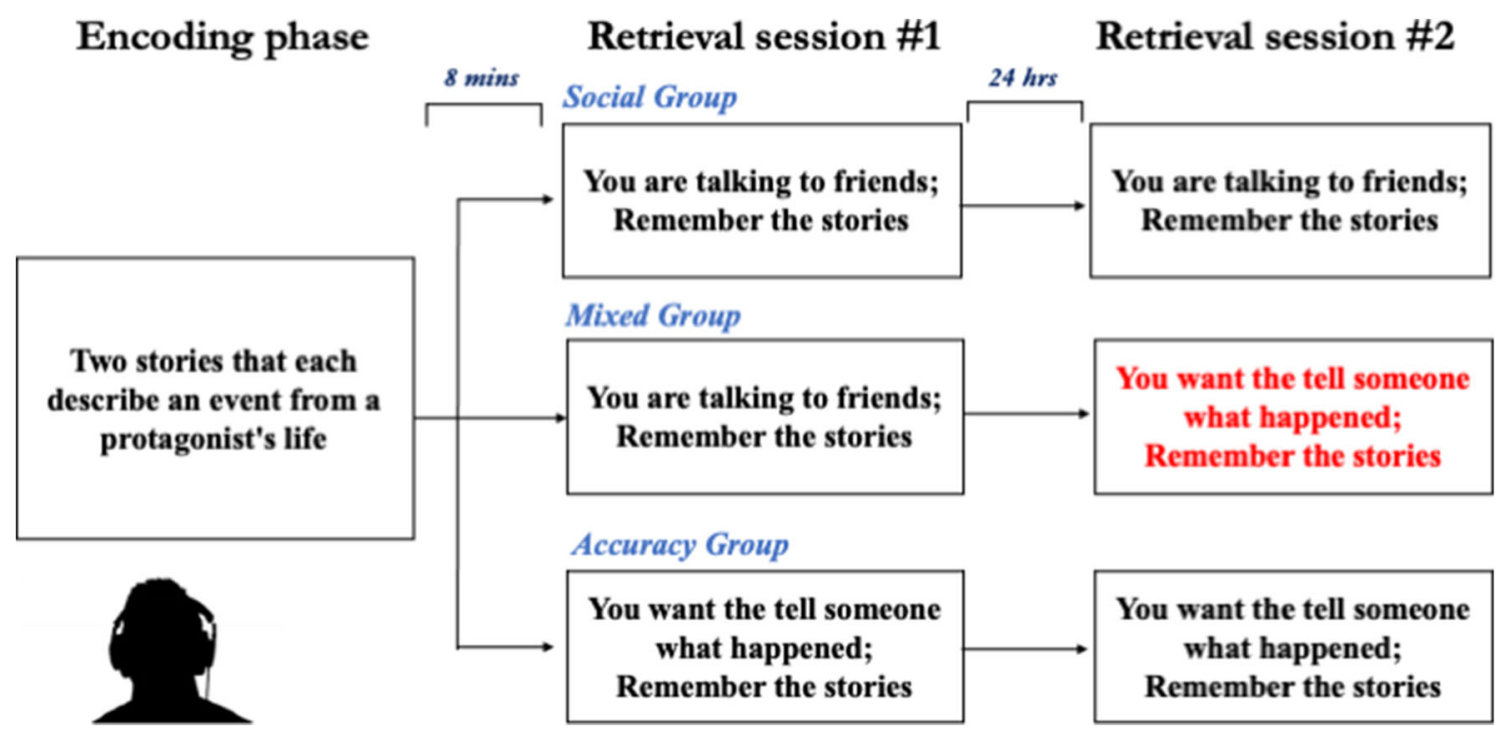

Fig. 1 An overview of the experimental design. All participants first listened to narratives describing life events of two fictional characters. Participants were then randomly assigned to either the social, mixed, or accuracy group, which determined their retrieval goals (i.e., the way in

Specific details describe the precise happenings of the story (e.g., recalling the detail "Lauri got a soda"). To further inspect how these details were described, we classified any specific detail that was elaborated upon with information implied from the story's details, but never explicitly stated (e.g., stating "Lauri was sitting at her desk" even though this was not a detail presented in the narrative) as an "elaboration." Scores were tallied for each of these categories and collapsed across both stories, giving a total score per session for each participant. Two experimenters coded the stories. Based on a random sample of stories, interrater agreement reached $93.6 \%$ (Cohen's $k=.85$ ) for specific details, 100\% (Cohen's $k=1$ ) for thematic units, and $97.1 \%$ agreement for elaboration details (Cohen's $k=.69$ ), suggesting there was substantial to near perfect agreement.

Detail order We also examined the order in which the details were recalled by calculating Pearson correlations between the order in which the details were recalled and the original detail order of each story. These correlations were averaged across stories (i.e., first transformed into Fisher $Z$ scores, averaged, then transformed back into correlations).

Narrative style scores Participants' recollections were submitted to the Linguistic Inquiry and Word Count tool (LIWC; Pennebaker et al., 2015) to examine analytical thinking and emotional tone (Pennebaker et al., 2014). Analytical thinking measures the formality of a given text sample, whereas emotional tone measures how positive or negative the overall content of a text is. These scores are expressed as percentiles, which were normed over a large sample. which they were to retrieve the narratives). Each narrative was described in detail after an 8-minute delay from hearing the stories (Session 1) and then again 24 hours later (Session 2)

\section{Planned analysis}

To test our hypotheses, we ran a series of mixed repeatedmeasures analyses of variance (RM ANOVAs) with session (1, 2) as a within-subjects factor and group (social, accuracy, mixed) as a between-subjects factor on the recollection variable of interest.

\section{Results}

\section{Data cleaning}

Visual inspection of the data as well as skewness and kurtosis scores revealed an adequately normal distribution (skewness $<$ $|3|$, kurtosis < |10|; Kline, 2011) based on the number of specific details recalled, thematic units recalled, and the detail order correlation for each session. Assumptions of equal variance and independence of datapoints were also satisfied.

\section{Details}

Results for each group, detail type (thematic, specific, elaborations) and detail order correlation in Sessions 1 and 2 are presented in Table 2. We first ran a mixed RM ANOVA, with group (social, accuracy, mixed) as a between-subjects factor and session $(1,2)$ as a within-subjects repeated measures factor on the average number of thematic units recalled across the narratives. This analysis revealed no main effect of session, $F(1,60)=0.98, p=.331, \eta^{2}=.001$, group, $F(2,60)=16.98, p$ 
$=.068, \eta^{2}=.07$, nor an interaction effect between group and session, $F(2,60)=1.95, p=.156, \eta^{2}=.00$.

We ran another mixed RM ANOVA, with session $(1,2)$ and group (social, accuracy, mixed) on the average number of specific details recalled. Although there was no main effect of session, $F(1,60)=2.77, p=.101, \eta^{2}=.00$, there was a main effect of group, $F(2,60)=10.00, p<.001, \eta^{2}=.23$, which was due to more specific details recalled in the accuracy than the mixed, $t(60)=3.63, p<.001$, and social groups, $t(60)=3.941, p<$ .001 . There was also a significant interaction between group and session, $F(2,60)=13.93, p<.001, \eta^{2}=.03$. We ran post hoc comparisons to further examine this interaction effect, using false-discovery rate (FDR) corrections (with a false-discovery rate of .05; Benjamini \& Hochberg, 1995). The scores discussed here remained significant after the FDR corrections, but the uncorrected $p$ values are reported. In Session 1, the social and mixed groups reported the same number of specific details, $t(69.4)=-1.55, p=.127$, which is not surprising given that both groups received the same instructions, and both reported fewer than the accuracy group - comparison to the social group, $t(69.4)$ $=3.51, p<.001$; comparison to the mixed group, $t(69.4)=4.62$, $p<.001$. In Session 2, the mixed and social groups reported the same number of specific details, $t(69.4)=1.22, p=.227$, while both the mixed group, $t(69.4)=2.36, p=.021$, and the social group, $t(69.4)=4.10, p<.001$, reported fewer specific details than the accuracy group (see Fig. 2).

We then ran a mixed RM ANOVA with session and group on the average elaboration details recalled. We found an effect of group, $F(2,60)=7.81, p<.001, \eta^{2}=.18$, where the social group differed from both the accuracy, $t(60)=-3.92, p<.001$, and the mixed groups, $t(60)=-2.15, p=.036$, such that more elaborations were generated in the social group than in the other groups (see Fig. 3). There was no main effect of session, $F(1,60)=1.36$, $p=.248, \eta^{2}=.00$, nor an interaction between session and group, $F(2,60)=2.88, p=.064, \eta^{2}=.10$.

Finally, to examine the order in which these details were recalled, we correlated the original detail order for each story (from 1 to 73) with the participants' recollection detail order

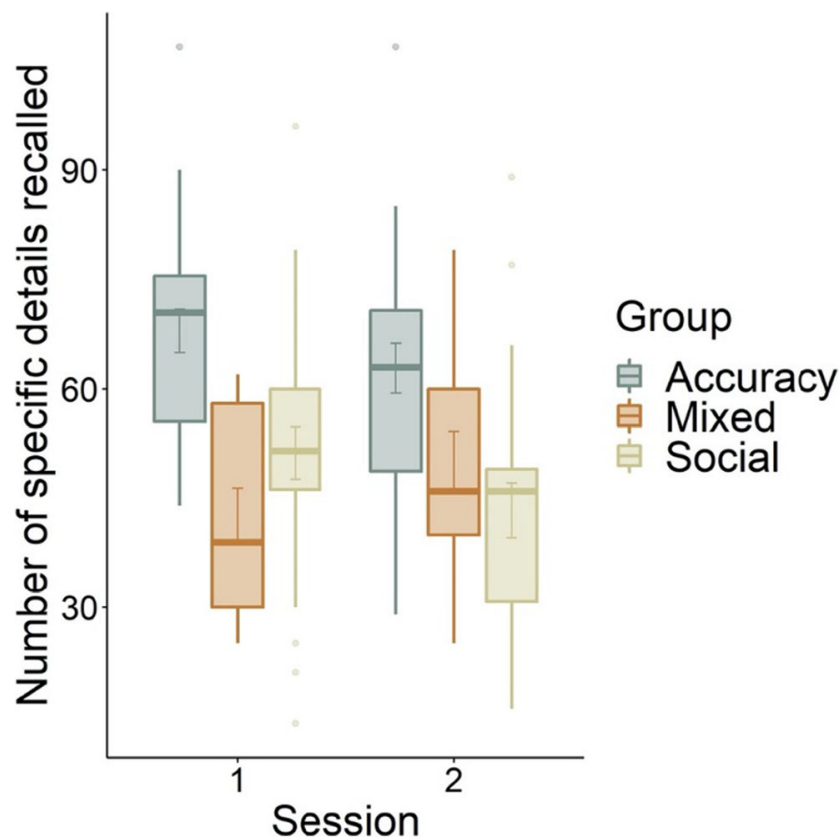

Fig. 2 Boxplots of the average number of specific details recalled from the narratives as a function of group for each retrieval session. The lower and upper box boundaries represent the 25 th and 75 th percentiles and the middle line represents the median

(from 1 to the last detail recalled) and computed an average score across stories to obtain averaged correlations for each session. We conducted a mixed RM ANOVA with group (social, accuracy, mixed) and session $(1,2)$ as factors on the average detail order correlations (see Table 1). There were no main effects of session, $F(1,60)=0.12, p=.731, \eta^{2}=.00$; however, there was a main effect of group, $F(2,60)=12.1, p<$ $.001, \eta^{2}=.18$, where participants in the social group recalled details with a lower detail order correlation than the mixed, $t(60)=2.96, p=.004$, and accuracy, $t(60)=4.83, p<.001$, groups. There was also an interaction effect between session and group, $F(2,60)=3.73, p=.030, \eta^{2}=.04$, such that the mixed and social groups did not differ in detail order in Session $1, t(118.2)=0.43, p=.668$, but were significantly

Table 2 Means $(M)$ and standard errors $(S E)$ of thematic units, specific details, elaborations, and detail order correlations.

\begin{tabular}{|c|c|c|c|c|c|c|c|c|}
\hline \multirow[t]{2}{*}{ Group } & \multicolumn{2}{|c|}{ Thematic units } & \multicolumn{2}{|c|}{ Specific } & \multicolumn{2}{|c|}{ Elaboration } & \multicolumn{2}{|c|}{ Detail order correlation } \\
\hline & $M$ & $S E$ & $M$ & $S E$ & $M$ & $S E$ & $M$ & $S E$ \\
\hline \multicolumn{9}{|l|}{ Session 1} \\
\hline Accuracy & 10.50 & 0.31 & 68.00 & 3.00 & 2.21 & 0.45 & 0.88 & 0.01 \\
\hline Mixed & 9.67 & 0.49 & 42.80 & 3.61 & 4.00 & 0.74 & 0.79 & 0.03 \\
\hline Social & 9.46 & 0.38 & 51.20 & 3.59 & 7.08 & 1.05 & 0.78 & 0.03 \\
\hline \multicolumn{9}{|l|}{ Session 2} \\
\hline Accuracy & 10.20 & 0.38 & 62.80 & 3.42 & 2.63 & 0.60 & 0.85 & 0.02 \\
\hline Mixed & 10.00 & 0.40 & 50.00 & 4.18 & 3.80 & 0.73 & 0.87 & 0.01 \\
\hline Social & 8.88 & 0.48 & 43.40 & 3.77 & 5.63 & 0.98 & 0.71 & 0.03 \\
\hline
\end{tabular}




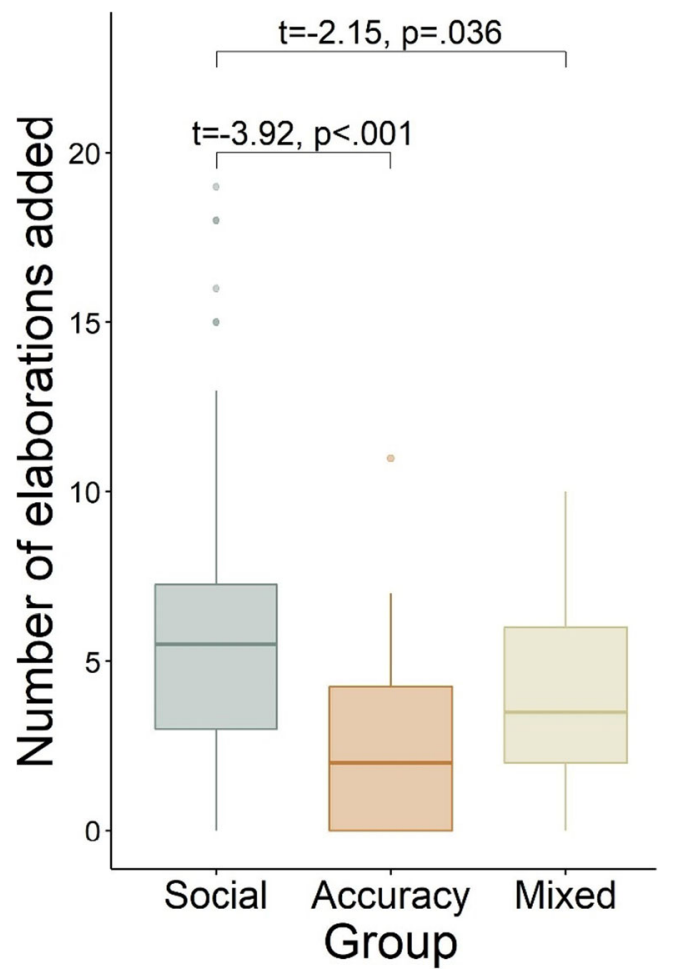

Fig. 3 Boxplots of the average number of elaborations given for the recalled narratives as a function of group, averaged across retrieval session. The lower and upper box boundaries represent the 25 th and 75th percentiles and the middle line represents the median

different in Session 2, $t(118.2)=4.00, p<.001$. Thus, the detail order correlation was higher for the mixed than social group during this session (see Fig. 4).

Ratings Table 3 describes the averages and standard errors for the collected ratings of the narratives as a function of group and session. For the enjoyment ratings, we ran an ANOVA with group (social, accuracy, mixed) as a factor and found no effect, $F(2,60)=0.78, p=.462, \eta^{2}=.03$. Mixed RM ANOVAs, with group and session $(1,2)$ as factors, were run on the vividness and emotional valence ratings that were collected across sessions. For the vividness ratings, we found an effect of session, $F(1,60)=43.95, p<.001, \eta^{2}=.11$, where stories were rated as less vivid in Session 2, but no effect of group, $F(2,60)=0.10, p=.901, \eta^{2}=.003$, or interaction between session and group, $F(2,60)=0.36, p=.702, \eta^{2}=$ .00 , emerged. For the emotional valence ratings, we found an effect of session, such that the stories were rated as less positive in Session 2, $F(1,60)=12.32, p<.001, \eta^{2}=.02$. There was no effect of group, $F(2,60)=0.1, p=.912, \eta^{2}=.003$, nor an interaction effect, $F(2,60)=0.45, p=.641, \eta^{2}=.00$.

Narrative style Table 4 describes the means and standard errors for the analyzed variables from the LIWC analysisAnalytical thinking (hereinafter referred to as Analytic) and Tone - as a function of group and session. The Analytic score

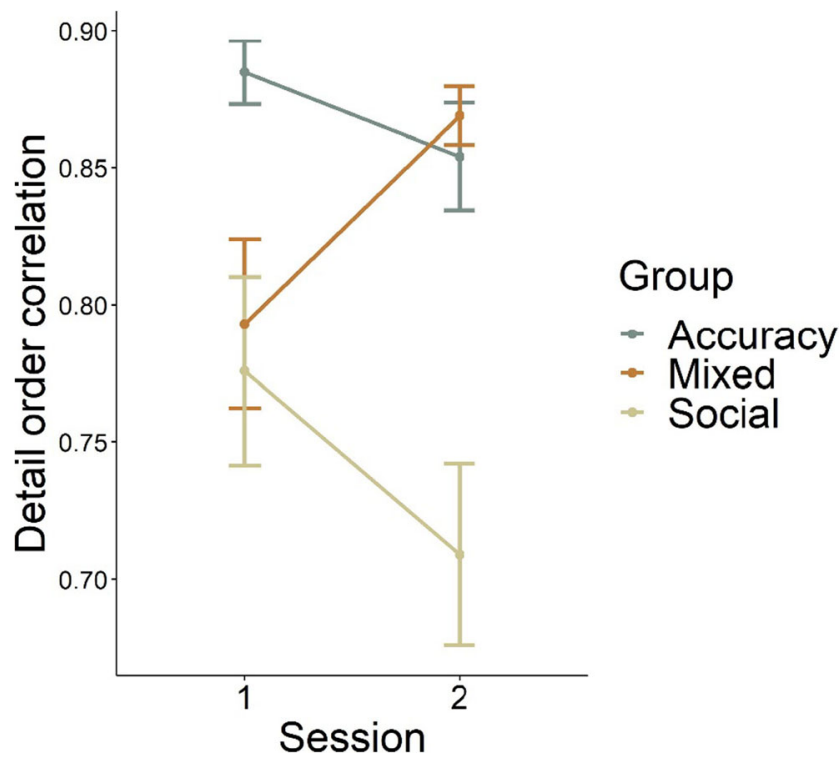

Fig. 4 A line graph illustrating the average detail order correlation in how the narratives were recalled as a function of group for each retrieval session. Standard errors are shown

describes how much a speaker uses formal and logical thinking, where a low Analytic score suggests more narrative-like descriptions. Past research has shown that a social retrieval goal encourages more narrative-like recollections. The literature also indicates that there is often a difference in Tone when comparing an accurate versus a social retrieval orientation, showing that social retrieval orientations induce more positive narratives than accurate ones (Dudukovic et al., 2004). Here, higher scores in Tone reflect more positive narratives.

To examine the Analytic scores, we ran aRM ANOVA, with session $(1,2)$ and group (accuracy, social, mixed) as factors. There was a main effect of group, $F(2,60)=8.78, p$ $<.001, \eta^{2}=.18$, where narratives in the accuracy group were more formal than narratives in both the mixed, $t(60)=3.12, p$ $=.003$, and social groups, $t(60)=3.89, p<.001$. There was also an effect of session, such that narratives were described in a more formal fashion in Session 2, $F(1,60)=4.72, p=.034$, $\eta^{2}=.02$. There was no significant interaction, $F(2,60)=1.19$, $p=.31, \eta^{2}=.01$. Next, we ran a RM ANOVA on the average Tone scores. We found an effect of group, $F(2,60)=3.74, p=$ $.03, \eta^{2}=.08$, indicating that the narratives described in the social group were more positive than those described in the accuracy group, $t(60)=-2.59, p=.012$.

\section{Discussion}

The current study provides new insight into the influence of retrieval goals, particularly social retrieval, on the content recalled from complex episodic memories. In a betweensubjects design, we compared the impact of two retrieval 
Table 3 Average $(M)$ and standard errors $(S E)$ for the enjoyment (Session 1 only), vividness, and emotional valence ratings of the narratives by retrieval session and group (each Likert rating was captured on a scale from 1 to 7)

\begin{tabular}{|c|c|c|c|c|c|c|c|c|c|c|}
\hline \multirow[t]{3}{*}{ Group } & \multicolumn{6}{|c|}{ Session 1} & \multicolumn{4}{|c|}{ Session 2} \\
\hline & \multicolumn{2}{|c|}{ Enjoyment } & \multicolumn{2}{|c|}{ Vividness } & \multicolumn{2}{|c|}{ Emotional valence } & \multicolumn{2}{|c|}{ Vividness } & \multicolumn{2}{|c|}{ Emotional valence } \\
\hline & $M$ & $S E$ & $M$ & $S E$ & $M$ & $S E$ & $M$ & $S E$ & $M$ & $S E$ \\
\hline Accuracy & 3.52 & 0.26 & 4.17 & 0.21 & 4.90 & 0.19 & 3.48 & 0.23 & 4.63 & 0.15 \\
\hline Mixed & 3.70 & 0.37 & 4.33 & 0.38 & 4.80 & 0.18 & 3.50 & 0.31 & 4.57 & 0.18 \\
\hline Social & 3.98 & 0.24 & 4.42 & 0.23 & 4.88 & 0.14 & 3.50 & 0.21 & 4.73 & 0.15 \\
\hline
\end{tabular}

goals, a social and accuracy goal, on the type and order of details recalled from narratives as well the narrative style used during retrieval. We further examined whether the effect of retrieval goals would persist after a 24-hour delay period, allowing for deeper consolidation of the narratives, as well as whether the effect would persist despite a change in the retrieval goal.

First, we found that a social goal reduced the number of specific details, but not central details (thematic units), recalled from a narrative when compared with an accuracy goal. A social goal also led to a higher number of detail elaborations (i.e., details not originally presented at encoding), in line with previous work suggesting that people in social contexts tend to add details or exaggerate a story (Marsh \& Tversky, 2004). Second, we found that a social goal altered the order in which these details were recalled, such that the details contained within a narrative recalled for a social purpose deviated more from the original order in which the details were encoded than when recall was guided by accuracy. Following suit, we found that narratives recounted to fit a social goal were described in a more positive and less formal style than narratives recounted to fit an accuracy goal.

In general, these results are in line with research indicating that retrieving a complex episodic memory - in this case, a narrative - is a dynamic process (Schacter \& Addis, 2007; Sheldon et al., 2019) that is influenced by retrieval context and goals (Pasupathi \& Hoyt, 2010; Dudukovic et al., 2004;

Table 4 Average $(M)$ and standard errors $(S E)$ for LIWC Analytic and Tone scores separated by session and group

\begin{tabular}{|c|c|c|c|c|c|c|c|c|}
\hline \multirow[t]{3}{*}{ Group } & \multicolumn{4}{|c|}{ Session 1} & \multicolumn{4}{|c|}{ Session 2} \\
\hline & \multicolumn{2}{|c|}{ Analytic score } & \multicolumn{2}{|c|}{ Tone score } & \multicolumn{2}{|c|}{ Analytic score } & \multicolumn{2}{|c|}{ Tone score } \\
\hline & $M$ & $S E$ & $M$ & $S E$ & $M$ & $S E$ & $M$ & $S E$ \\
\hline Accuracy & 52.8 & 3.41 & 49.20 & 2.33 & 55.60 & 3.52 & 49.20 & 2.11 \\
\hline Mixed & 34.3 & 4.31 & 49.80 & 4.02 & 44.10 & 4.68 & 51.20 & 2.72 \\
\hline Social & 37.00 & 3.21 & 55.60 & 3.17 & 38.50 & 3.49 & 59.30 & 2.75 \\
\hline
\end{tabular}

also see Elward \& Rugg, 2015; Gurguryan \& Sheldon, 2019). More specifically, we found that retrieving a memory with a social goal in mind enhanced memory distortions. Specifically, details reflecting the happenings of a story were removed or reordered, and narrative elaborations (i.e., false details) were more abundant (Dudukovic et al., 2004). Moreover, narratives recalled for a social retrieval goal led to more idiosyncratic recollections, as indicated by the detail order correlation analysis. A social goal did not, however, affect the central thematic elements (details) of a memory, suggesting that social recollections do not change the plot or overall gist of a memory. The lack of an effect on the central details suggests that these details are not prone to distortion, likely because they are important details that represent what occurred in a memory (Pillemer, 2003).

We also tested whether the effect of a social retrieval goal persisted when that goal was changed after a period of consolidation. When examining how these narratives were recalled in a second session, 24 hours after encoding and initial recall, we first found that the effect of a social retrieval goal on hindering recall of specific details was maintained. More importantly, when the retrieval goal was changed to an accuracy goal in Session 2 (mixed group), there was still a significant reduction in the ability to generate specific details. That is, initially retrieving a memory for a social goal impacts the content that can be recovered at a later timepoint, even when that goal has changed. There are several explanations for why the effect of a social retrieval goal in Session 1 led to fewer specific details recalled in Session 2, particularly for the group in which the goal had changed (mixed group). One possibility is that the retrieval goals given to participants induced a different strategy to recall the narratives. While we did not find that the mixed group recovered details when their goals had changed in Session 2, we did find that the mixed group changed how they recalled the narratives in Session 2. This was indicated by an enhanced tendency to recall the details in the same order as they were originally encoded, and provides new evidence that individuals alter how they recall narratives under different retrieval goals. 
Another explanation could be that it is a result of retrieval induced forgetting (RIF, e.g., Anderson, 2003; Anderson et al., 1994; Murayama et al., 2014). According to RIF, when cued to retrieve partial content of a memory, automatic inhibitory processes will impair access to the nonretrieved content. This effect is thought to reflect a retrieval strategy (Storm, 2011) and thus could explain why the mixed group could not recover previously unrecalled details from the narratives in Session 2; these details were inhibited during Session 1.

A final explanation could be that participants in the mixed group could not recover specific details from the narratives in Session 2 because the memory trace was altered during the initial retrieval session (for some related ideas, see Hardt et al., 2009; Loveday \& Conway, 2011; Tulving \& Pearlstone, 1966). Although an intriguing proposal, we cannot confirm whether participants were simply omitting details or that certain details were removed from a memory. To answer this question, a follow-up study could probe for specific details from the narratives with a recognition memory paradigm in Session 2.

\section{Conclusions, future questions, and limitations}

Our study adds to a body of work showing that we can flexibly retrieve a memory in a way that is congruent with our current goals and context. Here we show the effects of a social retrieval goal, an essential goal, for accessing and describing our experiences (Conway \& Pleydell-Pearce, 2000; Haque \& Conway, 2001). We found that memories recalled to a social goal were more simplified, idiosyncratic, and less formal in style than those recalled to an accuracy goal. We speculate that the reason for these changes in memory is to provide an entertaining story, which could help foster social bonds. To follow-up on this speculation, future research should examine how an individual's recollection of these narratives is perceived from an outside observer's perspective (e.g., are less accurate memories judged as more entertaining?). It is also important to note that we induced a social retrieval goal within a laboratory setting. Future research should test the effects of this type of retrieval in a more naturalistic setting (i.e., examining how a person recalls a narrative to a friend) as some research has done before (e.g., Pasupathi \& Hoyt, 2010; Pasupathi \& Oldroyd, 2015).

Future research could also address some of the methodological limitations of our study. First, we used retrieval cues that were general narrative titles. It is unclear how the results would have changed if participants were given more specific cues or asked more pointed questions about the stories. In addition, our instructions, though informed by previous research (Dudukovic et al., 2004), might have been somewhat leading, meaning participants' choice of omissions may have been partially influenced by the instructions rather than their own retrieval tendencies (i.e., implicit goals). Finally, the experimental conditions were tested in a blocked fashion, which make our results liable to biases based on the time of semester during which the students were tested.

While we focused on the social functions of memory, recalling experiences serves other useful purposes. Of note, memories are often recalled to inform a person's understanding of themselves (Conway \& Pleydell-Pearce, 2000; Habermas \& Bluck, 2000; McAdams, 2001). Whether retrieving memories for such a function similarly leads to inaccurate remembering is an interesting avenue for future work.

Acknowledgements The authors would like to thank Daria Lisus and Caterina Agostino for assistance with data collection and scoring, as well as Willem Le Duc and Kevin Da Silva Castanheira for help recording the stimuli.

Availability of data and materials Data and material will be made available upon personal request.

Code availability Not applicable.

Authors' contributions S.S. and E.D. conceptualized the study, E.D. tested participants and analyzed data, and E.D. and S.S. wrote the manuscript.

Funding This work was supported by a Natural Sciences and Engineering Research Council (NSERC) Discovery grant (\#RGPIN04241) awarded to S. Sheldon.

\section{Declarations}

Conflicts of interest The authors have no conflicts of interest to disclose.

Ethics approval This project was approved by the McGill Research Ethics Board (REB\#: 186-0918)

Consent to participate Informed consent was obtained from all individual participants included in the study.

Consent for publication The authors affirm that human research participants provided informed consent for publication of their data.

\section{References}

Adams, C., Smith, M. C., Nyquist, L., \& Perlmutter, M. (1997). Adult age-group differences in recall for the literal and interpretive meanings of narrative text. The Journals of Gerontology: Series B, Psychological Sciences and Social Sciences, 52(4), P187-P195. https://doi.org/10.1093/geronb/52b.4.p187

Alba, J. W., \& Hasher, L. (1983). Is memory schematic? Psychological Bulletin, 93(2), 203-231. https://doi.org/10.1037/0033-2909.93.2.203

Alea, N., \& Bluck, S. (2003). Why are you telling me that? A conceptual model of the social function of autobiographical memory. Memory, 11(2), 165-178. https://doi.org/10.1080/74193820

Anderson, M. C. (2003). Rethinking interference theory: Executive control and the mechanisms of forgetting. Journal of Memory and Language, 49(4), 415-445. https://doi.org/10.1016/j.jml.2003.08.006

Anderson, M. C., Bjork, R. A., \& Bjork, E. L. (1994). Remembering can cause forgetting: Retrieval dynamics in long-term memory. Journal 
of Experimental Psychology: Learning, Memory, and Cognition, 20, 1063-1087. https://doi.org/10.1037/0278-7393.20.5.1063

Benjamini, Y., \& Hochberg, Y. (1995). Controlling the false discovery rate: A practical and powerful approach to multiple testing. Journal of the Royal Statistical Society: Series B (Methodological), 57(1), 289-300. https://doi.org/10.1111/j.2517-6161.1995.tb02031.x

Bluck, S., \& Alea, N. (2002). Exploring the functions of autobiographical memory: Why do I remember the autumn? In J. D. Webster \& B. K. Haight (Eds.), Critical advances in reminiscence work: From theory to application (pp. 61-75). Springer.

Bluck, S., Alea, N., Habermas, T., \& Rubin, D. C. (2005). A tale of three functions: The self-reported uses of autobiographical memory. Social Cognition, 23(1), 91-117. https://doi.org/10.1521/soco.23. 1.91 .59198

Burke, A., Heuer, F., \& Reisberg, D. (1992). Remembering emotional events. Memory \& Cognition 20, 277-290. https://doi.org/10.3758/ BF03199665

Christianson, S.-Å. (1992). Emotional stress and eyewitness memory: A critical review. Psychological Bulletin, 112(2), 284-309. https://doi. org/10.1037/0033-2909.112.2.284

Conway, M. A., \& Pleydell-Pearce, C. W. (2000). The construction of autobiographical memories in the self-memory system. Psychological Review, 107(2), 261-288. https://doi.org/10.1037/ 0033-295X.107.2.261

Conway, M. A., Cohen, G., \& Stanhope, N. (1991). On the very longterm retention of knowledge acquired through formal education: Twelve years of cognitive psychology. Journal of Experimental Psychology: General, 120(4), 395-409. https://doi.org/10.1037/ 0096-3445.120.4.395

Dudai, Y., \& Eisenberg, M. (2004). Rites of passage of the engram: Reconsolidation and the lingering consolidation hypothesis. Neuron, 44(1), 93-100. https://doi.org/10.1016/j.neuron.2004.09. 003

Dudukovic, N. M., Marsh, E. J., \& Tversky, B. (2004). Telling a story or telling it straight: The effects of entertaining versus accurate retellings on memory. Applied Cognitive Psychology, 18(2), 125-143. https://doi.org/10.1002/acp.953

Elward, R. L., \& Rugg, M. D. (2015). Retrieval Goal Modulates Memory for Context. Journal of Cognitive Neuroscience, 27(12), 25292540. https://doi.org/10.1162/jocn_a_00878

Gurguryan, L., \& Sheldon, S. (2019). Retrieval orientation alters neural activity during autobiographical memory recollection. NeuroImage, 199, 534-544. https://doi.org/10.1016/j.neuroimage.2019.05.077

Habermas, T., \& Bluck, S. (2000). Getting a life: The emergence of the life story in adolescence. Psychological Bulletin, 126(5), 748-769. https://doi.org/10.1037/0033-2909.126.5.748

Haque, S., \& Conway, M. A. (2001). Sampling the process of autobiographical memory construction. European Journal of Cognitive Psychology, 13(4), 529-547. https://doi.org/10.1080/ 09541440125757

Hardt, O., Wang, S.-H., \& Nader, K. (2009). Storage or retrieval deficit: The yin and yang of amnesia. Learning \& Memory, 16(4), 224-230. https://doi.org/10.1101//m.1267409

Heuer, F., \& Reisberg, D. (1992). Emotion, arousal, and memory for detail. In S.-Å. Christianson (Ed.), The handbook of emotion and memory: Research and theory (p. 151-180). Erlbaum.

Kline, R. B. (2011). Principles and practice of structural equation modeling (4th ed., Methodology in the social sciences). (pp.7477). Guilford Press.

Loftus, E. F., Miller, D. G., \& Burns, H. J. (1978). Semantic integration of verbal information into a visual memory. Journal of Experimental Psychology: Human Learning and Memory, 4(1), 19-31. https://doi. org/10.1037/0278-7393.4.1.19

Loveday, C., \& Conway, M. A. (2011). Using SenseCam with an amnesic patient: Accessing inaccessible everyday memories. Memory, 19(7), 697-704. https://doi.org/10.1080/09658211.2011.610803
Marsh, E. J. (2007). Retelling is not the same as recalling: Implications for memory. Current Directions in Psychological Science, 16(1), 1620. https://doi.org/10.1111/j.1467-8721.2007.00467.x

Marsh, E. J., \& Tversky, B. (2004). Spinning the stories of our lives. Applied Cognitive Psychology, 18(5), 491-503. https://doi.org/10. 1002/acp.1001

Marsh, E. J., Tversky, B., \& Hutson, M. (2005). How eyewitnesses talk about events: Implications for memory. Applied Cognitive Psychology, 19(5), 531-544. https://doi.org/10.1002/acp.1095

McAdams, D. P. (2001). The psychology of life stories. Review of General Psychology, 5(2), 100-122. https://doi.org/10.1037/10892680.5.2.100

Murayama, K., Miyatsu, T., Buchli, D., \& Storm, B. C. (2014) Forgetting as a consequence of retrieval: A meta-analytic review of retrievalinduced forgetting. Psychological Bulletin, 140(5), 1383-1409. https://doi.org/10.1037/a0037505

Pasupathi, M., \& Hoyt, T. (2010). Silence and the shaping of memory: How distracted listeners affect speakers' subsequent recall of a computer game experience. Memory (Hove, England), 18(2), 159-69. https://doi.org/10.1080/09658210902992917

Pasupathi, M., \& Oldroyd, K. (2015). Telling and remembering: complexities in long-term effects of listeners on autobiographical memory. Applied Cognitive Psychology, 29(6), 835-842. https://doi.org/ 10.1002/acp.3193

Pennebaker, J. W., Chung, C. K., Frazee, J., Lavergne, G. M., Beaver, D. I., \& Gong, Q. E. (2014). When small words foretell academic success: The case of college admissions essays. PLOS ONE, 9(12), e115844. https://doi.org/10.1371/journal.pone.0115844

Pennebaker, J. W., Boyd, R. L., Jordan, K., \& Blackburn, K. (2015). The development and psychometric properties of LIWC2015. University of Texas Press.

Pillemer, D. B. (2001). Momentous events and the life story. Review of General Psychology, 5(2), 123-134. https://doi.org/10.1037/10892680.5.2.123

Pillemer, D. (2003). Directive functions of autobiographical memory: The guiding power of the specific episode. Memory, 11(2), 193202. https://doi.org/10.1080/741938208

Prebble, S. C., Addis, D. R., \& Tippett, L. J. (2013). Autobiographical memory and sense of self. Psychological Bulletin, 139(4), 815-840. https://doi.org/10.1037/a0030146

Rudoy, J. D., Weintraub, S., \& Paller, K. A. (2009). Recall of remote episodic memories can appear deficient because of a gist-based retrieval orientation. Neuropsychologia, 47(3), 938-941. https://doi. org/10.1016/j.neuropsychologia.2008.12.006

Schacter, D. L., \& Addis, D. R. (2007). The cognitive neuroscience of constructive memory: Remembering the past and imagining the future. Philosophical Transactions of the Royal Society B: Biological Sciences, 362(1481), 773-786. https://doi.org/10.1098/rstb.2007. 2087

Schacter, D. L., Guerin, S. A., \& St. Jacques, P. L. (2011). Memory distortion: An adaptive perspective. Trends in Cognitive Science, 15(10), 467-474. https://doi.org/10.1016/j.tics.2011.08.004

Sekeres, M. J., Bonasia, K., St-Laurent, M., Pishdadian, S., Winocur, G., Grady, C., \& Moscovitch, M. (2016). Recovering and preventing loss of detailed memory: Differential rates of forgetting for detail types in episodic memory. Learning \& Memory (Cold Spring Harbor, N.Y.), 23(2), 72-82. https://doi.org/10.1101/lm.039057. 115

Sheldon, S., Gurguryan, L., \& Fenerci, C. (2019). Different forms and functions of autobiographical memory retrieval. Frontiers in Systems Neuroscience, 13(4). https://doi.org/10.3389/fnsys.2019. 00004

Speer, N. K., \& Zacks, J. M. (2005). Temporal changes as event boundaries: Processing and memory consequences of narrative time shifts. Journal of Memory and Language, 53(1), 125-140. https://doi.org/ 10.1016/j.jml.2005.02.009 
Storm, B. C. (2011). The benefit of forgetting in thinking and remembering. Current Directions in Psychological Science, 20(5), 291-295. https://doi.org/10.1177/0963721411418469

Thorndyke, P. W. (1977). Cognitive structures in comprehension and memory of narrative discourse. Cognitive Psychology, 9(1), 77110. https://doi.org/10.1016/0010-0285(77)90005-6

Tulving, E., \& Pearlstone, Z. (1966). Availability versus accessibility of information in memory for words. Journal of Verbal Learning and Verbal Behavior, 5(4), 381-391. https://doi.org/10.1016/S00225371(66)80048-8
Tversky, B., \& Marsh, E. J. (2000). Biased retellings of events yield biased memories. Cognitive Psychology, 40(1), 1-38. https://doi. org/10.1006/cogp.1999.0720

Wade, E., \& Clark, H. H. (1993). Reproduction and demonstration in quotations. Journal of Memory and Language, 32(6), 805-819.

Wechsler, D. (2009). WMS-IV: Wechsler memory scale (4th ed.). Pearson.

Publisher's note Springer Nature remains neutral with regard to jurisdictional claims in published maps and institutional affiliations. 